\title{
Skills and Strategies Used in the Comprehension and Production of Academic Writing in Taif University
}

\author{
Sawsan Amin Ahmed ${ }^{1} \&$ A. Alamin ${ }^{1}$ \\ ${ }^{1}$ Department of English, Taif University, KSA \\ Correspondence: Sawsan Amin Ahmed, Department of English, Taif University, KSA. E-mail: \\ sawsanamin2002@yahoo.ca
}

Received: January 19, 2012

Accepted: February 15, $2012 \quad$ Online Published: August 21, 2012

doi:10.5539/ells.v2n3p134

URL: http://dx.doi.org/10.5539/ells.v2n3p134

\begin{abstract}
The paper examines the skills and strategies that are employed in the comprehension and the production of the writing tasks at the undergraduate levels. Through diary keeping the strategies and skills were explored and the resulting written assignments were analyzed. The sample was limited to students who base their writing assignment on prompts given by their instructors. They are considered at the intermediate level. The themes used while they are writing their diary. "What strategies do they use in the process of composing academic writing"'What difficulties do they encounter while they are writing those assignments". The findings can be used as a guide in future planning for writing classes. In order to develop skills such as critical thinking, errors in grammar should not be the base for the final grading.
\end{abstract}

Keywords: strategies of writing, comprehending writing assignments, skills employed in academic writing

\section{Reviewing the Literature}

Academic writing in general and Literary writing in particular have been given some attention by researchers and educators in recent years, but that attention is far from being sufficient to nurture an advanced skill such as writing. Although the two types of writing demand different sets of skills to accomplish the required tasks, they share one single element which is the use of the English language. In spite of the innovative books that are used in Taif University which are learner centered and communicatively constructed, the students are still relying on rote memorization, work closely with books, and remain reluctant to analyze, comment on, or critique a scholarly book. They lack the freedom of expression that stems from confidence in their abilities to use English.

In this paper, through diary keeping, is going to gain insight into the strategies used by the students, compare them to the strategies and processes of thinking mentioned in recent literature. The data is then going to be analyzed and recommendations are drawn to bring them to teachers' and educators' attention.

\section{Writing as an Advanced Skill}

Writing in general and Academic writing in particular are considered the most advanced of the four skills, listening, speaking, and reading and writing. In addition, there is an impression that the language skills are hierarchically sequenced, with writing viewed as the last skill to be practiced and mastered (Casanave \& Hubbard, 1992, p. 33).

\section{Literary Reviews}

Based on the requirements of the instructor, the Literature Review (LR) can be:

1. A simple summary of the sources, where the student is not required to indicate his or her opinion.

2. Sometimes the Literature Review LR has an organizational pattern and combines both summary and synthesis. Those are often what are required at the higher levels of undergraduate levels.

A summary recapitulates the important information of the source, but a synthesis is a re-organization of that information. The student might give a new interpretation of the old material or combine new material with old interpretations. Or the student might trace the intellectual progression of the field, including his or her ideas for debates. Sometimes the instructor asks the students to evaluate the sources and advise the reader on the most relevant points in the discussion. 


\section{The Academic Research Paper}

The main focus of an academic research paper is to develop a new argument which is not required in the (LR), It shares one common feature with the LR paper in that it contains a literature review as one of its parts. In a research paper, RL can be used as a foundation, to demonstrating how the previous research is related to the study... a framework for viewing the study" (Brown, 1988, p. 46). They provide support for a new insight where a new contribution can be made. The focus of a LR, however, is to summarize and synthesize the arguments and ideas of others without adding new contributions.

\section{The ESL Strategies in Academic writing}

The strategies employed by college students are diverse. Learners use some of their L1 writing strategies to deal with the demands of the L2 assignments. Leki (1995) believes that students are even capable of modifying their strategies and develop new ones to achieve the desired results. Researchers have looked at factors and mental activities that go into developing a strategy. They also tried to group them or subdivide them.

O'Mally, and Chamot in 1990 defined learning strategies as "any set of operations, steps, plans, or routines used by the learner to facilitate the obtaining, storage, or retrieval and use of information" (109). Cagne, on the other hand, sees strategies as skills that the learner uses to regulate his or her internal processes of learning, skills such as remembering, and thinking. A third opinion relates to Best who implies that "strategies are seen as behavior, but such a behavior implies some mental activity or effort (1977, p. 35).

Rubin, 1975, Cohen, 1998, Wenden 1991 claims that learning strategies are unobservable, but some may be associated with an observable behavior. For example, a learner could use selective attention which is considered an unobservable skill to focus on the main ideas while listening to a lecture for instance, and then decides to take notes which at that point could be described as an observable skill. In almost all learning contexts, the only way to find out whether students are using learning strategies while engaged in a language task is for the interviewer to ask them or getting them to document their process of thinking. Verbal report data are used to identify language learning strategies because observation does not capture mental processes (Wenden and Rubin, p. 222).

\subsection{The Scope of the Study}

The distinction has to be made between learner's strategy and learning strategy: Tarone (1981) made the distinction between three sets of learner strategies: learning strategy, production strategy, and communication strategy. According to this view, the learner employs:

First: A learning strategy which is the means by which the learner processes second language (L2) input.

Second: Production strategy which is the learner's attempt to use the knowledge already acquired to accomplish the writing assignment.

Third: Communication strategy which consists of the learner's attempt to communicate meanings beyond their linguistic competence by using devices such as paraphrasing and gesture (Faerch and Kasper, 1983, 72-73).

This paper addresses how the learner processes the knowledge which is going to be used for a writing assignment i.e. the input. Furthermore, the production strategy is going to be touched upon.

\subsection{Cognition and Learning Strategies}

Moving towards the more cognitive view of strategy, In 1983 Mclaghlin, Roseman, \& Mcleod, suggested a model for "information processing approach" where the learner is viewed as an active organizer of incoming information with processing limitation and capabilities. Motivation is considered an important element in succeeding, however, the learner's cognitive system is central to processing. The learner is able to store and retrieve information depending on the degree to which the information is processed. One implication of information processing is that the learners actively impose cognitive schema on incoming data in an effort to organize the information. A schema is defined as a mental construct. The term is used by cognitive psychologists in their theories of memory and learning (pp. 208-209).

\subsection{Comprehension and schema}

When the written assignment or the targeted text to be analyzed is being explained, the students try to comprehend the information and figure out a way to decide what is considered important or not. An easy way to understand comprehension on the behalf of the learner is to characterize it. It is useful to characterize comprehension because comprehension is a learning process in which prior knowledge plays an important role. A schema can be thought of as a knowledge structure, or framework, which interrelates all of one's knowledge about a given topic. The prior knowledge organized in schemata, in turn influences the form and content of the 
new knowledge. Experienced learners achieve automaticity by employing two kinds of learning strategies. The first is top-down approach (or knowledge governed systems) which makes use of internal schemata. In such a process the learner 'brings to' a text background knowledge which he or she utilizes in the interpretation of its meaning. The second is the bottom-up approach (or an input-governed system) which makes use of external input. In such a process listener attends to individual words and structures in the text itself, using these to build up an interpretation. In either case cognition is involved, but the degree of cognitive involvement is set by the interaction between the requirements of the task and the knowledge and mental processes used by the learner (Richgdels, 1982, p. 54).

Wong Fillmore (1982) specified strategies that are described in more general terms rather the specific terms described in the cognitive psychology and include: general knowledge and mental skills as well as strategic processes. He suggests that such strategies include: associative skills, memory, social knowledge, inferential skills, analytical skills, ... pattern recognition, induction, categorization, generalization and so on (p. 37).

\section{Ways to Zero in on Learning Strategies}

Researchers have asked language learners to describe their learning processes and strategies. The task proved to be daunting until a few techniques were developed to document the mental processes used to accomplish the task at hand. Grenfell and Harris stated that language learning strategies are identified through self report. Although self-report may be inaccurate if the learner does not report truthfully, it is still the only way to identify learners' mental processing. As they indicated that:

[...] it is not easy to get inside ... the human brain and find out what is going on there. We work with what we can get, which, despite the limitations, provides food for thought (qutd. Chamot, 2004, p. 23).

A few of the techniques can be identified as useful to elicit the mental processes that help learners deal with the writing tasks. Such techniques include: interviews that took several forms such as, stimulated recall interviews, questionnaires, written diaries and journals, and think-aloud protocols that were done simultaneously done with a learning task. Each of these methods has limitations, but each provides important insights into unobservable mental learning strategies.

\section{The Sample}

The participants were three students selected from Taif University, the Kingdom of Saudi Arabia, in the girl's campus. Various levels were chosen. One student (May) from the fourth level which is the equivalent the second term of the second year of a four year program at the English Department, Faculty of Arts. The second, (Meha) student was from the sixth level which represents the second term of the third year and the third (Reem) from the eighth level that equals to the last term in the four year program (all Pseudonyms). All participants have learned English for at least nine years and had experiences in writing.

\subsection{Limitations of the Research}

The sample was limited to students who base their writing assignment on prompts given by their instructor whether it be an RL based on a literary text or in the linguistics discipline where the learner has to base her research paper or article on literature presented to them in the lecture. The three selected students are considered-being in the second year university as minimum level chosen- within the category of an intermediate level. However, lower levels have writing courses, but in these courses, the writing is not based on cues given by the instructor Although the writing follows a certain pattern of organization and development like writing a narrative, or an argumentation-persuasion essay, non-the less, the writing process is starting from a scratch and the thoughts could be random.

\section{Thoughts on the Research}

Taif University has been relying heavily on instructors from Arabic speaking countries. They are mainly bilingual so they speak the language of the students. Therefore, tasks and assignments are clarified easily using Arabic. During the last few years the university has attracted many non-Arabic speaking instructors, where the students are forced to interact in English, tried to critically think, draw conclusions and come up with reviews and papers to match the internationally accepted requirements. That is when the need became apparent that a probe into the strategies used in academic writing is necessary.

\section{Procedures}

By using the diary keeping method the participants were first asked to document their thought as the lecture is going on as to what strategy they are using to decipher the new information. The instructors were advised to let the sample students know that the information presented in that particular session is going to be asked for in an 
assignment. Later on, as they are embarking on the assignment required by their instructor, they are asked to write down their thoughts again. The diary method is designed to leave a space for comments on the process of thought; before and during, the writing assignment. The diaries provided a reasonably structured data across the participants. They provided an in depth account of the process of writing richer than that obtained by other methods (Gall et al., 1996). The research was conducted in the second term of the academic year 2010-2011.

\subsection{Strategies}

The sample students mentioned a few methods that they used to figure out the requirements of the academic assignment. While they are writing their diary they are asked to keep three questions in mind:

1. What is the student's perception of the requirements of academic writing?

2. What the challenges that are facing them in meeting the requirements of academic writing?

3. What strategies do they use to in the process of composing academic writing?

The induced assignments were: one in the field of literature an assignment on "school for scandal" where they were asked to comment on the theme and the other assignment is in the discipline of linguistics; a paper on dialects used in Saudi society outlining differences in Age, Gender and generation. The three resulting papers were analyzed in terms of ideational content such as; the originality of ideas, progression of thought, and clarity of expressions. The papers further were looked at in terms of grammar, and writing mechanics.

Throughout the diaries some techniques were documented as part of comprehension and writing ones these are:

Communications with the supervisor: One of the most methods used by the participants is communicating with the instructor to inquire about the specifics of what is required to be done.

Imitation: One of the strategies mentioned in the diaries is imitation, where the student reads similar reviews borrowed from previous years to find out how the writers tackle similar topics and then imitate the structures used. While this method gets the student through the task at hand, "it is not considered the best way to go about creative thinking; however, it is a good way to assimilate the materials of relevant genre conventions and subject knowledge" (Shaw, 1991, p. 168).

Translation: One of the students admitted that she writes the assignment in Arabic then she uses machine translation to convert it to English. All three have admitted they have translated parts of the texts to be analyzed or all of it to reach an understanding of the concepts presented in it.

\section{Findings and Discussion}

The discussion is going to be divided into two parts the first part is going to represent the students' thought when they are presented with the information to be analyzed for the assignment. The second part is going to represent their thoughts when writing the topics. According to all three learners; writing in English is similar to writing in Arabic. They also indicated that all the components that make up the writing process such as the formulation, development and organization of ideas are important.

The comprehension part indicated that two out of the three participants think down upwardly except one Meha, uses in top down terms. Two learners have used their past experiences as guides to deal with new assignments, while Meha concentrated on the language itself.

\subsection{Comprehension Challenges}

As for the comprehension phase the learners had some challenges but had a fair idea of what is expected of them. They have focused on what they were told emphasize on in their assignment.

May indicated that:

$$
\begin{aligned}
& \text { "I realize the assignments are ways for learning English } \\
& \text { so, while I listen to the instructor's explanation, I try to figure out } \\
& \text { what needs to be learned here... Even when I start writing I try to } \\
& \text { touch on the areas emphasized by the instructor. Most of the } \\
& \text { times I miss the important points." }
\end{aligned}
$$

Similar thoughts were documented by Reem as she wrote:

"I try to find what the instructor emphasizes. If the point is repeated

I know what to focus on in writing." 
Meha's thoughts went a different direction as she mentioned:

\section{"I hear the entire lesson anything can be important if you have the}

language to write about it... I see what other students think.

Sometimes they hear points I miss. Then I choose

my points."

According to Boote \& Belie 2006, Swales \& Feak 2000, the student's understanding of the writing tasks compare to the existing literature that academic writing tasks are intended to introduce past works done on issues and distinguishes the student's own writing by producing his /her own rationale.

\subsection{Writing Challenges}

However, during the actual writing task the learners faced the most trouble. May wrote:

"Its hard to write, to pick out words... the idea is clear in the mind

but to write it down is difficult ... The structures sometimes are

wrong. That is when you lose the most marks. Most of the times, the

grammar is correct but you don't get good marks.

Reem mentioned a different problem altogether when she addressed the issue of the actual writing.

"I know the idea but it is hard to write it correctly. The teachers tell

you how to develop your paragraphs but when you write your

sentences they say you have included not important ideas or

you have missing ideas."

Meha wrote:

"Everything is difficult in writing. The thinking doesn't come.

The sentences come out wrong because the grammar is difficult.

Even if the grammar is correct it is hard to know what the teacher

wants. The words are difficult to choose."

\section{The Difficulties}

The diaries presented a number of difficulties the learners have encountered. These comprise:

Lack of clarity of the requirements of academic writing: It is apparent that the learners had clear ideas of what is important in terms of the focal points of the texts, but they lack the creativity that goes into academic writing. The ideas are tackled in a unified manner i.e. similar points were mentioned in all assignments. It appears that students have worked close to the book with little room to think individually. Sometimes the problem lies in the choice of style or paragraph development as what is appropriate for one discipline may not be appropriate for the other. It would appear that the instructors are "rewarding" the learners for following stilted patterns rather than to think individually to come up with new concepts. Such individuality in thinking patterns yields errors. However, keeping the writing limited to a few themes would yield error free writing and that is what the instructors base the grade on.

Grammatical difficulties: The structural difficulties were the rippling effect of "playing it safe" on the behalf of the students because creating an original idea will need expressions that don't come from the notes taken in the lectures. The main concern however, was the correctness of their writing. According to Gu, (2002) there are some elements that contribute to students' writing such as vocabulary acquisition; but such skills do not provide the necessary grammatical information of the context that the learner might need when expressing thoughts for their own writing. The students need to be reminded that writing requires more than familiarity with lists of vocabulary they need "familiarity with their meaning and form" (Schmitt \& McCarthy, 1997, p. 4).

\section{Recommendations}

A few notes emerged as a result of this research; they point to the fact that both instructors and learners are of the opinion that keeping the ideas simple and the language clear of errors is a safe way to ensure success. It also might mean that if the students were not given an impromptu they will not be able to produce an assignment. They need cues to base their writing on. Whatever the case might be a few techniques may help: 
1. Reading sample reviews with sessions of guided discussion can give guidance to students. These sessions will help learners in techniques such as critical thinking and conclusion drawing. Those in effect will stimulate the learners to think more freely in terms of content rather than the language of the writing.

2. Although the students were taught early in the learning process about the requirements of academic writhing, they need to be reminded of what is acceptable and what is not. For instance, none of the participants have used any kind of prewriting organizational activity. Furthermore, each genre needs a certain kind of organization for its writing so, the students need to comply with the norms without losing sight of having the freedom of expression.

\section{References}

Brown, J. D. (1988). Understanding research in second language learning. A teachers guide to statistics and research design. Cambridge: Cambridge University Press.

Boote, D. N., \& Beile, P. (2006). On "Literature reviews of, and for, educational research": A response to the critique by Joseph Maxwell. Educational Researcher, 35(9), 32-35.

Cagne, R. M. (1977). The conditions for learning ( ${ }^{\text {rd }}$ ed). New York: Holt Rinehart and Winston.

Casanave, C. P., \& Hubbard, P. (1992). The writing assignments and writing problems of doctoral students. Faculty perceptions, pedagogical issues, and needed research. English for Specific Purposes, 11(1), 39-49.

Chamot, A. U. (2004). Issues in language learning strategy research and teaching. Electronic Journal of Foreign Language Teaching, 1(1), 14-26.

Faerch, C., \& Kasper G. (1983). Strategies in interlanguage communication. London: Longman.

Gall, M. D., Borg, W. R., \& Gall, J. P. (1996). Educational research: An introduction (6th ed.). White Plains, NY: Longman.

Gu, Y. (2002). Gender, academic major, and vocabulary learning strategies of Chinese EFL learners. RELC journal, 33(1), 35-54.

Leki, L. (1995). Coping with strategies of ESL students in writing tasks across the curriculum, TESOL Quarterly, 29, 235-260.

McLaughlin, B., Rossman, T., \& McLeod, B. (1983). Second language learning: An information-processing perspective. 36(2), 135-158.

O’Malley, J. M., \& Chamot, A. U. (1990). Learning strategies in second language acquisition. Cambridge: Cambridge University Press.

Rubin, J. (1975). What a good language learner can teach us. TESOL Quarterly, 9, 41-51.

Shaw, P. (1991). Science research students' composing processes. English for Specific Purpose, 10, 189-206.

Schmitt, N., \& McCarthy, M. (Eds.). (1997). Vocabulary: Description acquisition and pedagogy. Cambridge: Cambridge University Press.

Swales, J. M., \& Feak, C. B. (2000). English in today's research: A writing guide. Ann Arbor, MI: University of Michigan Press.

Richgels, D. J. (1982). Schema theory, theory and representations of reading comprehension. Journal of Educational Research, 7(1), 54-62.

Wenden, A. L. (1998). Metacognitive knowledge and language learning. Applied Linguistics, 19(4), 515-537.

Tarone, E. (1981). Thoughts on the notion of communication strategy. TESOL Quarterly, 15, 285-295.

Wong Fillmore, L. (1982). Instructional language as linguistic input: second-language learning in classrooms. In L.C. Wilkinson (Ed.), Communicating in the classroom: Language, thought and culture (pp. 283-296). New York: Academic. 